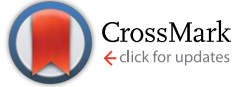

Cite this: J. Mater. Chem. B, 2015, 3, 449

Received 10th October 2014 Accepted 4th November 2014

DOI: $10.1039 / c 4 t b 01680 \mathrm{~g}$

www.rsc.org/MaterialsB

\section{New insights into the cross-linking and degradation mechanism of Diels-Alder hydrogels $\uparrow$}

\author{
Susanne Kirchhof, a Andrea Strasser, ${ }^{\mathrm{b}}$ Hans-Joachim Wittmann, ${ }^{\mathrm{b}}$ Viktoria Messmann, ${ }^{\text {a }}$ \\ Nadine Hammer, ${ }^{a}$ Achim M. Goepferich ${ }^{a}$ and Ferdinand P. Brandl ${ }^{\star a}$
}

\begin{abstract}
Eight-armed poly(ethylene glycol) was functionalized with furyl and maleimide groups. The two macromonomers were cross-linked by Diels-Alder (DA) reactions and the degradation behavior of the formed hydrogels was investigated. UV spectroscopy showed that maleimide groups were subject to ring-opening hydrolysis above $\mathrm{pH} 5.5$, with the reaction rate depending on the $\mathrm{pH}$ and temperature. As a result of this, the gelation kinetics and stiffness of DA hydrogels were dependent on the temperature and the $\mathrm{pH}$ of the cross-linking medium, as demonstrated by rheological experiments. The gel time varied

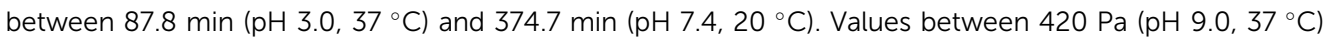
and $3327 \mathrm{~Pa}\left(\mathrm{pH} 3.0,37^{\circ} \mathrm{C}\right)$ were measured for the absolute value of the complex shear modulus. Hydrogel swelling and degradation were influenced by the same parameters. With increasing $\mathrm{pH}$ and temperature the degradation time was reduced from 98 days $\left(\mathrm{pH} 7.4,20^{\circ} \mathrm{C}\right)$ to 2 days $\left(\mathrm{pH} 7.4,50{ }^{\circ} \mathrm{C}\right)$; no degradation was observed at $\mathrm{pH} 3.0$ and 5.5. Molecular modeling studies of the DA and retro-DielsAlder (rDA) moieties revealed that hydrogel degradation occurred by rDA reaction followed by $\mathrm{OH}^{-}$catalyzed ring-opening hydrolysis of maleimide groups to unreactive maleamic acid derivatives.
\end{abstract}

\section{Introduction}

The concept of click chemistry has, without doubt, revolutionized macromolecular synthesis and materials science. ${ }^{\mathbf{1 - 4}}$ The reasons for the importance of click reactions are their wide scope, their high efficiency and selectivity, and the ease of purification of the resulting products. Furthermore, it is advantageous that click reactions can be conducted in aqueous media under mild conditions (e.g., at room temperature). Besides azide-alkyne cycloadditions and thiol-ene reactions, Diels-Alder (DA) reactions, which rely on carbon-carbon bond formation between conjugated dienes and substituted alkenes, have been frequently applied in macromolecular synthesis., ${ }^{\mathbf{5} 6}$ For instance, the DA reaction has been used for the synthesis of block copolymers and dendrimers, the surface modification of nanoparticles, ${ }^{7-9}$ and the preparation of hydrogels. ${ }^{\mathbf{1 0 - 1 4}}$ Interestingly, the DA reaction and its counterpart, the retro-Diels-Alder (rDA) reaction, are reversible under certain conditions (e.g., at elevated temperature or in organic solvents). The DA/rDA equilibrium has been exploited, e.g., for the synthesis of recyclable, mendable or self-healing materials. ${ }^{\mathbf{1 5 - 1 7}}$ Furthermore, the DA/

\footnotetext{
${ }^{a}$ Department of Pharmaceutical Technology, Faculty of Chemistry and Pharmacy, University of Regensburg, 93040 Regensburg, Germany. E-mail: ferdinand.brandl@ ur.de; Fax: +49 941 943-4807; Tel: +49941 943-4920

${ }^{b}$ Department of Pharmaceutical and Medicinal Chemistry II, Faculty of Chemistry and Pharmacy, University of Regensburg, 93040 Regensburg, Germany

$\dagger$ Electronic supplementary information (ESI) available. See DOI: 10.1039/c4tb01680g
}

rDA reaction has been used for the protection/deprotection of maleimide groups, which allowed the preparation of methacrylate-based thiol-reactive hydrogels. ${ }^{18-20}$ The rDA fragmentation has also been explored for the purpose of binding and release drugs from macromolecular carriers. ${ }^{21}$ And recently, the DA/rDA system has been proposed as a mechanism to control the release of drug molecules from poly(ethylene glycol) (PEG)-based hydrogels. $^{22,23}$

Despite the reversibility of the DA/rDA reaction, hydrogels cross-linked by DA reactions did not readily degrade by rDA reactions as the rate of these reactions is too slow at body temperature. In order to achieve degradation, multiple rDA reactions must occur simultaneously at significant rate, which is unlikely in highly cross-linked networks. This limited the scope of the DA/rDA reaction to situations compatible with high temperatures and required the introduction of hydrolytically or enzymatically cleavable sites to render the hydrogels biodegradable. For example, hydrogels with hydrolytically cleavable ester bonds decomposed in acid or basic media, with the degradation rate being controlled by the $\mathrm{pH}$ of the solution. ${ }^{10}$ In a slightly different approach, furan-modified hyaluronic acid (HA) derivatives were cross-linked with dimaleimide PEG $^{\mathbf{1 1 , 2 4}}$ or maleimide-functionalized HA. ${ }^{12}$ The resulting hydrogels degraded in the presence of hyaluronidase and might be suitable for applications in regenerative medicine.

In our previous work, we investigated the DA reaction as a cross-linking mechanism for PEG-based hydrogels. ${ }^{13}$ Two complementary macromonomers were synthesized by 
functionalizing star-shaped PEG of two different branching factors (four-armed and eight-armed PEG) and two different molecular weights (10 kDa and $20 \mathrm{kDa})$ with furyl and maleimide groups. Hydrogels were prepared by step-growth polymerization of the synthesized macromonomers and characterized with regard to their mechanical properties, average network mesh size and swelling behavior. Somewhat surprising, the cross-linked hydrogels degraded in phosphate buffer, pH 7.4 at $37^{\circ} \mathrm{C}$, with the degradation time depending on the number of moles of elastically active chains. NMR analysis of the degradation products revealed the presence of furyl groups whereas no maleimide groups could be detected. Instead we observed two new signals that were assigned to newly generated maleamic acid groups. While maleimide is a strong dienophile, maleamic acid (ring-open form of maleimide) is much less reactive in DA reactions ${ }^{22,25}$ and no hydrogel formation is observed. Based on these findings, two potential pathways for the degradation of DA hydrogels can be formulated (Scheme 1).

In pathway $\mathrm{A}$, the $\mathrm{DA}$ adduct first undergoes $\mathrm{rDA}$ reaction (reaction I). In a second step, $\mathrm{OH}^{-}$is added to the carbonyl moiety of the formed maleimide (reaction IIa), which is then subject to a ring-opening reaction yielding furan and unreactive maleamic acid (reaction IIIa). In pathway $\mathrm{B}, \mathrm{OH}^{-}$is first added to the carbonyl moiety of the DA adduct (reaction IIb). The formed complex is then subject to ring opening (reaction IIIb) and subsequent rDA reaction yielding furan and unreactive maleamic acid (reaction IV).

Herein we present new insights into the cross-linking and degradation mechanism of PEG-based DA hydrogels. In the first experiment, the hydrolytic stability of PEG-maleimide was investigated at different $\mathrm{pH}$-values and temperatures. Next, we

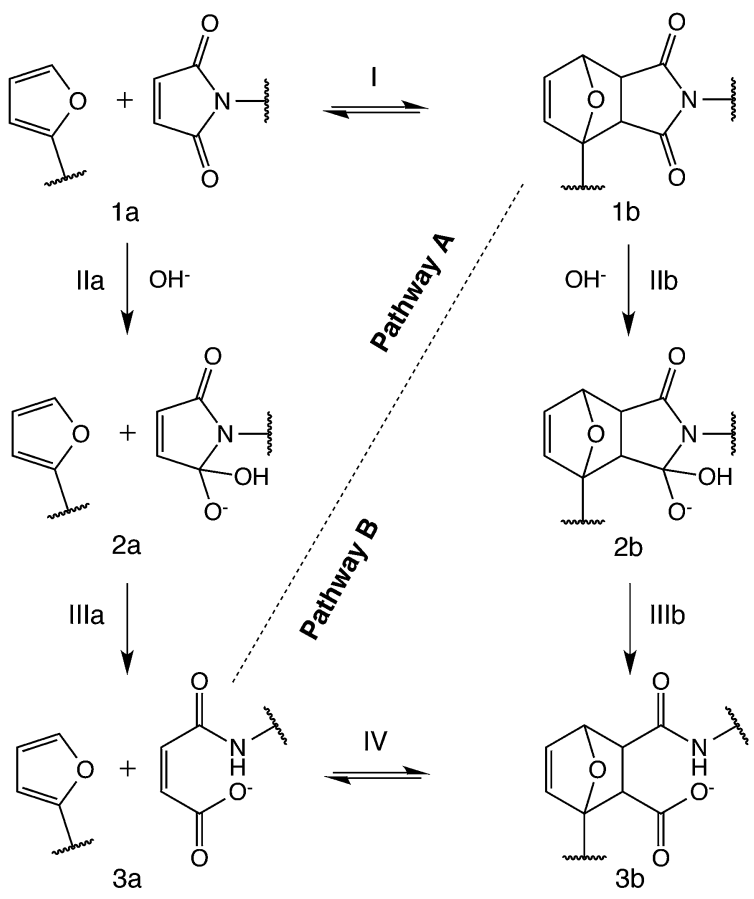

Scheme 1 Potential degradation pathways of DA hydrogels. studied the influence of $\mathrm{pH}$ and temperature on the crosslinking kinetics and stiffness of DA hydrogels. Based on the obtained results, in-depth degradation studies were performed at different $\mathrm{pH}$-values and temperatures. The experiments were supplemented with semi-empirical molecular dynamics (SEMD) simulations of the DA and rDA complexes at basic $\mathrm{pH}$. In the following, we will present the results of these studies and discuss which pathway (Scheme 1) hydrogel degradation most likely follows.

\section{Experimental section}

\section{Materials}

Eight-armed PEG, molecular weight $10 \mathrm{kDa}$ (hexaglycerol core, 8armPEG10k-OH) was purchased from JenKem Technology (Allen, TX, USA) and functionalized with furyl (8armPEG10kfuran) and maleimide groups (8armPEG10k-maleimide) as previously described. ${ }^{13}$ Citric acid and sodium dihydrogen phosphate monohydrate were received from Merck KGaA (Darmstadt, Germany). 2-(N-Morpholino)ethanesulfonic acid (MES) was purchased from Sigma-Aldrich (Taufkirchen, Germany). Water was obtained by using a Milli-Q water purification system from Millipore (Schwalbach, Germany).

\section{Hydrolytic stability of 8armPEG10k-maleimide}

The hydrolytic stability of 8armPEG10k-maleimide was determined by UV spectroscopy. For stability testing, $20 \mathrm{mg}$ of 8armPEG10k-maleimide were dissolved in $2 \mathrm{~mL}$ of $50 \mathrm{mM}$ citrate buffer (pH 3.0), $50 \mathrm{mM}$ MES buffer ( $\mathrm{pH} 5.5)$ or $50 \mathrm{mM}$ phosphate buffer ( $\mathrm{pH} 7.4, \mathrm{pH} 9.0$ and $\mathrm{pH}$ 11.0). The samples were placed in a Kontron UVIKON ${ }^{\circledR} 941$ spectrophotometer (Kontron Instruments S.p.A, Milan, Italy) equipped with a temperature-controlled cell changer; $10 \mathrm{~mm}$ quartz cuvettes were used. The decrease in the absorbance at $299 \mathrm{~nm}$ (UV maximum of 8armPEG10k-maleimide) was monitored for $1200 \mathrm{~min}$ at $37^{\circ} \mathrm{C}$. To determine the temperature dependence of hydrolysis, $20 \mathrm{mg}$ of 8 armPEG10k-maleimide were dissolved in $2 \mathrm{~mL}$ of $50 \mathrm{mM}$ phosphate buffer ( $\mathrm{pH} 7.4)$. The decrease in the absorbance was monitored at $20{ }^{\circ} \mathrm{C}, 30{ }^{\circ} \mathrm{C}, 40{ }^{\circ} \mathrm{C}$ and $50{ }^{\circ} \mathrm{C}$ as described above. All measurements were performed in triplicate and the obtained data was normalized. Assuming that the $\mathrm{pH}$ of the buffered solutions does not change during hydrolysis (constant $\mathrm{OH}^{-}$concentration), pseudo-first-order kinetic models were least-squares fitted to the experimental data to determine the hydrolysis rate constants $\left(k_{\text {obs }}\right)$ and half-lives $\left(t_{1 / 2}\right)$ of 8armPEG10k-maleimide. The plateau value was shared between all groups and $k_{\mathrm{obs}}$ was set greater than zero.

\section{Rheological characterization of DA hydrogels}

To study the influence of the $\mathrm{pH}$ of the cross-linking medium on gelation kinetics and mechanical properties, oscillatory shear experiments were performed on a TA Instruments AR 2000 rheometer (TA Instruments, Eschborn, Germany) with parallel plate geometry ( $40 \mathrm{~mm}$ in diameter, $500 \mu \mathrm{m}$ gap size). For the measurements, equal molar amounts of 8armPEG10k-furan $(19.0 \mathrm{mg})$ and 8armPEG10k-maleimide (18.5 $\mathrm{mg})$ were 
dissolved in $750 \mu \mathrm{L}$ of $50 \mathrm{mM}$ citrate buffer (pH 3.0), $50 \mathrm{mM}$ MES buffer (pH 5.5) or $50 \mathrm{mM}$ phosphate buffer (pH 7.4, pH 9.0 and $\mathrm{pH}$ 11.0). After the hydrogel precursor solution had been cast onto the lower plate of the rheometer, the upper plate was immediately lowered to a gap size of $500 \mu \mathrm{m}$ and the experiment was started. A solvent trap was used to minimize water evaporation. The time evolution of storage modulus $\left(G^{\prime}\right)$ and loss modulus $\left(G^{\prime \prime}\right)$ was recorded at $37^{\circ} \mathrm{C}$ and an oscillatory frequency of $1.0 \mathrm{~Hz}$. The crossover of $G^{\prime}$ and $G^{\prime \prime}$ was regarded as the gel point; the absolute value of the complex shear modulus $\left(\left|G^{*}\right|\right)$ was determined after the maximum value had been reached. To study the influence of the temperature, the rheological measurements were repeated in $50 \mathrm{mM}$ MES buffer ( $\mathrm{pH}$ 5.5) and $50 \mathrm{mM}$ phosphate buffer ( $\mathrm{pH} 7.4$ ) at $20^{\circ} \mathrm{C}$. All experiments were performed in triplicate and the results are shown as means \pm standard deviations.

\section{Swelling and degradation of DA hydrogels}

For swelling and degradation studies, equal molar amounts of 8armPEG10k-furan (114.3 mg) and 8armPEG10k-maleimide (110.7 mg) were dissolved in $4500 \mu \mathrm{L}$ of water. Directly after mixing, $375 \mu \mathrm{L}$ of the liquid precursor solutions were filled into cylindrical glass molds ( $7 \mathrm{~mm}$ inner diameter) and allowed to gel for $72 \mathrm{~h}$ under standard cell culture conditions $\left(37^{\circ} \mathrm{C}, 95 \%\right.$ relative humidity and $5 \% \mathrm{CO}_{2}$ ). The gel cylinders were weighed ( $t=0$ days), immersed in $10 \mathrm{~mL}$ of $50 \mathrm{mM}$ citrate buffer ( $\mathrm{pH}$ 3.0), $50 \mathrm{mM}$ MES buffer ( $\mathrm{pH} 5.5$ ) or $50 \mathrm{mM}$ phosphate buffer $(\mathrm{pH}$ 7.4, pH 9.0 and $\mathrm{pH} 11.0)$ and incubated at $37{ }^{\circ} \mathrm{C}$ in a shaking water bath (approximately $10 \mathrm{rpm}$ ). To determine the influence of temperature on hydrogel degradation, gel cylinders were prepared as described above, immersed in $10 \mathrm{~mL}$ of $50 \mathrm{mM}$ phosphate buffer ( $\mathrm{pH} \mathrm{7.4)}$ and incubated at $20^{\circ} \mathrm{C}, 30^{\circ} \mathrm{C}, 40{ }^{\circ} \mathrm{C}$ or $50{ }^{\circ} \mathrm{C}$. The vials were emptied over $24 \mathrm{~mm}$ Netwell-Inserts (500 $\mu \mathrm{m}$ mesh size, Corning GmbH, Kaiserslautern, Germany) at periodic time points, the gel cylinders were weighed, and incubated again with $10 \mathrm{~mL}$ of fresh buffer solution. The experiment was continued until no macroscopic gel residues could be detected on the Netwell-Inserts. All experiments were performed in triplicate and the results are presented as means \pm standard deviations.

\section{Molecular modeling studies}

To minimize the calculation time, the polymer structures of 8armPEG10k-furan and 8armPEG10k-maleimide were reduced to 2-methylfuran and $N$-methylmaleimide, respectively. All complexes were constructed with SYBYL 7.0 (Tripos Inc., St. Louis, MO) and pre-minimized using the Tripos force field. Subsequently, the resulting structures were converted into a MOPAC (Stewart Computational Chemistry, Colorado Springs, $\mathrm{CO}$ ) input file. Using the keyword line " $t=1000 \mathrm{am} 1 \mathrm{pdb}$ mmok gnorm $=0.1$ eps $=78$ charge $=-1$ " the complexes were minimized in order to obtain the enthalpy of formation. In setting up the system for the SEMD simulation using the MOPAC 2009 package, the complex of interest was solvated with a water shell consisting of about 60 water molecules and showing the density of water at $25{ }^{\circ} \mathrm{C}$. The relative molar mass of the atoms of the water molecules in the outer hydration shell was set to 9999 in order to avoid expansion of the system. The simulations were performed for $>10 \mathrm{ps}$ in all cases.

\section{Statistical analysis}

The results of the rheological characterization were analyzed by means of one-way ANOVA followed by Tukey's post-hoc test (GraphPad Prism, Version 5.01, GraphPad Software Inc., La Jolla, CA). The differences were considered statistically significant at $p<0.05$.

\section{Results and discussion}

\section{Hydrolytic stability of 8armPEG10k-maleimide}

To investigate the possible degradation pathways, we first studied the hydrolytic stability of 8armPEG10k-maleimide. It is well known from the literature that maleimides and $\mathrm{N}$-alkylmaleimides hydrolyze in alkaline solution. ${ }^{26-28}$ However, data on the hydrolytic stability of 8armPEG10k-maleimide is still

\section{A}

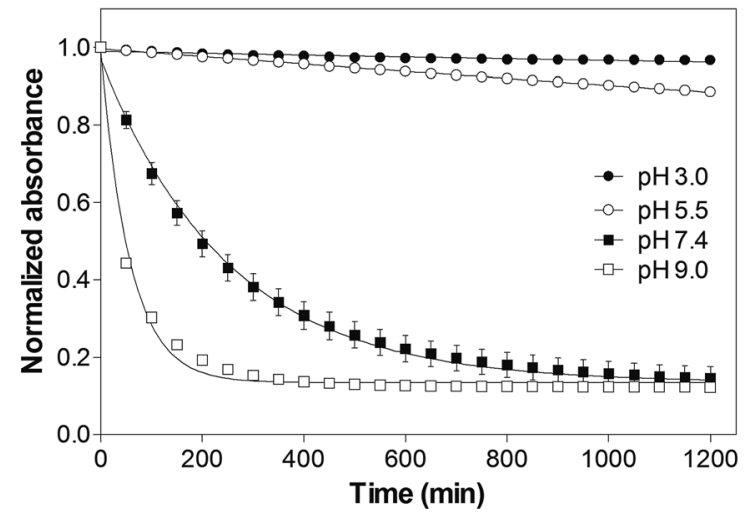

B

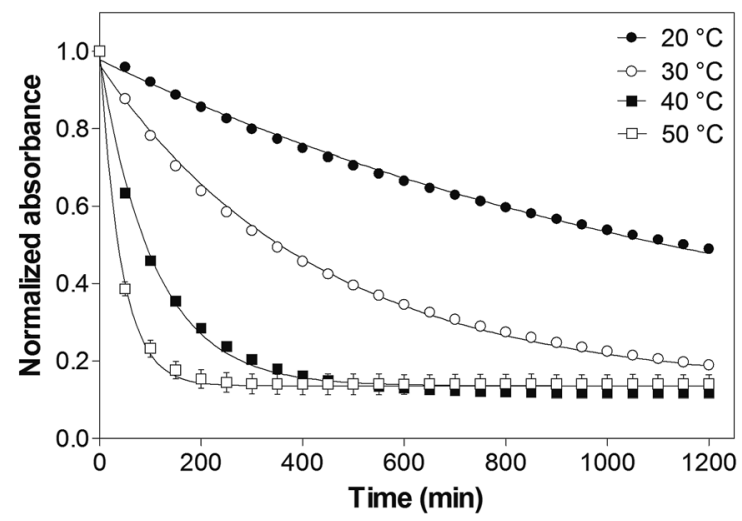

Fig. 1 Hydrolytic stability of 8 armPEG10k-maleimide at $37^{\circ} \mathrm{C}$ and different $\mathrm{pH}$-values (A), and at $\mathrm{pH} 7.4$ and different temperatures (B). The experimental data is indicated by symbols; the solid lines represent the least-squares fits of pseudo-first-order kinetic models. The experiments were carried out in triplicate and the results are presented as means \pm standard deviations. 
missing. The hydrolytic ring opening of 8armPEG10k-maleimide is a key step in degradation pathway A and can be easily followed by UV spectroscopy (Fig. 1A). When 8armPEG10kmaleimide was incubated at $\mathrm{pH} 3.0$ or $\mathrm{pH} 5.5$, the absorbance at $299 \mathrm{~nm}$ slowly decreased indicating high stability of the maleimide. At $\mathrm{pH}$ 7.4, the absorbance decreased more rapidly indicating faster hydrolysis of the maleimide in comparison to $\mathrm{pH} 3.0$ and $\mathrm{pH}$ 5.5. When the $\mathrm{pH}$ was further increased to $\mathrm{pH}$ 9.0, 8armPEG10k-maleimide was subject to fast ring opening as indicated by the rapidly decreasing absorbance. At pH 11, the hydrolytic ring opening of 8armPEG10k-maleimide was extremely fast and reliable measurements could not be made (data not shown). Besides the $\mathrm{pH}$, the stability of 8armPEG10kmaleimide was found to depend on the incubation temperature. When the temperature was increased from $20{ }^{\circ} \mathrm{C}$ to $50{ }^{\circ} \mathrm{C}$, the rate of hydrolysis increased likewise (Fig. 1B).

Since the concentrations of $\mathrm{OH}^{-}$and $\mathrm{H}_{3} \mathrm{O}^{+}$are constant during the reaction in buffered solutions, it is reasonable to assume that the hydrolysis of 8armPEG10k-maleimide follows the pseudo-first-order eqn (1).

$$
-\frac{\mathrm{d}[8 \operatorname{armPEG} 10 \mathrm{k}-\text { maleimide }]}{\mathrm{d} t}=k_{\mathrm{obs}}[8 \operatorname{armPEG} 10 \mathrm{k}-\text { maleimide }]
$$

$$
k_{\mathrm{obs}}=k\left[\mathrm{OH}^{-}\right]
$$

Rate constants $\left(k_{\mathrm{obs}}\right)$ and half-lives $\left(t_{1 / 2}\right)$ were calculated by fitting the integrated form of eqn (1) to the experimental data (Tables 1 and 2). Our results clearly show that the rate of the ring-opening reaction increases with increasing $\mathrm{pH}$ and temperature. Since the reaction rate is not negligible at neutral $\mathrm{pH}$ and room temperature, hydrolysis of maleimide groups to unreactive maleamic acid derivatives may play an important role during cross-linking and degradation of DA hydrogels.

Table 1 Pseudo-first-order rate constants $\left(k_{\text {obs }}\right)$ of the ring-opening hydrolysis and half-lives $\left(t_{1 / 2}\right)$ of 8 armPEG10k-maleimide at $37^{\circ} \mathrm{C}$ and different $\mathrm{pH}$-values

\begin{tabular}{llrll}
\hline $\mathrm{pH}$ & $k_{\mathrm{obs}}\left(\mathrm{s}^{-1}\right)$ & $t_{1 / 2}(\mathrm{~min})$ & $3 t_{1 / 2}($ days $)$ & $R^{2}$ \\
\hline 3.0 & $4.83 \times 10^{-7}$ & 26358 & 54.9 & 0.7630 \\
5.5 & $1.92 \times 10^{-6}$ & 6020 & 12.5 & 0.9989 \\
7.4 & $6.55 \times 10^{-5}$ & 177 & 0.4 & 0.9813 \\
9.0 & $2.60 \times 10^{-4}$ & 44 & 0.1 & 0.9764
\end{tabular}

Table 2 Pseudo-first-order rate constants $\left(k_{\text {obs }}\right)$ of the ring-opening hydrolysis and half-lives $\left(t_{1 / 2}\right)$ of 8 armPEG1OK-maleimide at pH 7.4 and different temperatures

\begin{tabular}{lllll}
\hline$T\left({ }^{\circ} \mathrm{C}\right)$ & $k_{\text {obs }}\left(\mathrm{s}^{-1}\right)$ & $t_{1 / 2}(\mathrm{~min})$ & $3 t_{1 / 2}(\mathrm{days})$ & $R^{2}$ \\
\hline 20 & $1.24 \times 10^{-5}$ & 929 & 1.9 & 0.9969 \\
30 & $3.81 \times 10^{-5}$ & 303 & 0.6 & 0.9979 \\
40 & $1.47 \times 10^{-4}$ & 79 & 0.2 & 0.9926 \\
50 & $3.85 \times 10^{-4}$ & 30 & 0.1 & 0.9652
\end{tabular}

\section{Rheological characterization of DA hydrogels}

The influence of the $\mathrm{pH}$ on cross-linking kinetics and stiffness of DA hydrogels was investigated by oscillatory shear experiments at $37{ }^{\circ} \mathrm{C}$. As shown in Fig. 2A, the gel time was not significantly different at $\mathrm{pH} 3.0, \mathrm{pH} 5.5$ and $\mathrm{pH} 7.4$; values between $87.8 \pm 8.2 \mathrm{~min}(\mathrm{pH} \mathrm{3.0)}$ ) and $97.2 \pm 6.5 \mathrm{~min}(\mathrm{pH} 7.4)$ were observed. The gel time increased to $207.6 \pm 21.5 \mathrm{~min}$ at pH 9.0, which was significantly longer compared to the three lower $\mathrm{pH}$-values $(p<0.05)$. When the $\mathrm{pH}$ was further increased to 11.0 , no gel formation was observed within $4 \mathrm{~h}$ (data not shown). The stiffness of the cross-linked hydrogels generally decreased with increasing $\mathrm{pH}$ (Fig. 2B). The absolute value of $G^{*}(3328 \pm 373 \mathrm{~Pa})$ was significantly higher at $\mathrm{pH} 3.0$ than in all other experimental groups $(p<0.05)$. When the $\mathrm{pH}$ was raised to 5.5 , the absolute value of $G^{*}$ decreased to $2517 \pm 176 \mathrm{~Pa}$; however, this value was still significantly higher than at $\mathrm{pH} 7.4$ and $\mathrm{pH} 9.0(p<0.05)$. Further increasing the $\mathrm{pH}$ resulted in mechanically weaker hydrogels. The magnitude of $G^{*}$ decreased to $685 \pm 169 \mathrm{~Pa}$ at $\mathrm{pH} 7.4$, which was not significantly different from that value at $\mathrm{pH} 9.0(420 \pm 205 \mathrm{~Pa})$.

For step-growth polymerizations of $f$-functional species, the conversion of functional groups at the gel point $(\alpha)$ can be calculated according to the Flory-Stockmayer theory: ${ }^{29}$

$$
\alpha=\frac{1}{f-1}
$$

According to eqn (3), gelation of DA hydrogels made from eight-armed PEG $(f=8)$ occurs at approximately 15\% conversion of both furyl and maleimide groups. The time to reach the gel point, which is approximated by the crossover of $G^{\prime}$ and $G^{\prime \prime}$, can be used to describe the kinetics of cross-linking. In crosslinked networks, the absolute value of $G^{*}$ relates to the number of elastically active chains, which can be calculated from the degree of cross-linking or conversion of functional groups. ${ }^{29}$ Oscillatory shear experiments can, therefore, be used to describe the kinetics of cross-linking and to approximate the conversion of functional groups. In our experiments, both the kinetics of cross-linking and the conversion of functional groups were greatly influenced by the $\mathrm{pH}$ (Fig. 2A and B). While Brønsted acid catalysis of DA reactions was reported in both polar and nonpolar organic solvents, ${ }^{30-32}$ no general Brønsted acid catalysis was observed in water. The rate constants for the DA reaction between cyclopentadiene and dienophiles with basic sites were considerably faster in $0.01 \mathrm{M} \mathrm{HCl}$ than in pure water; however, no Brønsted acid catalysis was detected in the DA reaction of cyclopentadiene with non-basic naphthoquinones. ${ }^{33}$ Since neither furan nor maleimide contain any basic sites, acid catalysis of the DA reaction between 8armPEG10k-furan and 8armPEG10k-maleimide is unlikely. Furthermore, acid catalysis may explain the faster reaction kinetics at acidic $\mathrm{pH}$ but not the higher magnitude of $G^{*}$. However, $\mathrm{pH}$-dependent ring opening of maleimide groups and generation of unreactive maleamic acid derivatives can explain the observed results. In the sol state at pH 3.0, pH 5.5 and $\mathrm{pH}$ 7.4 , the ring-opening reaction is slow compared to the DA 
A

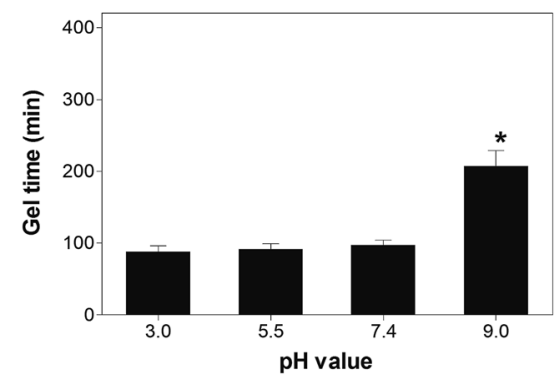

C

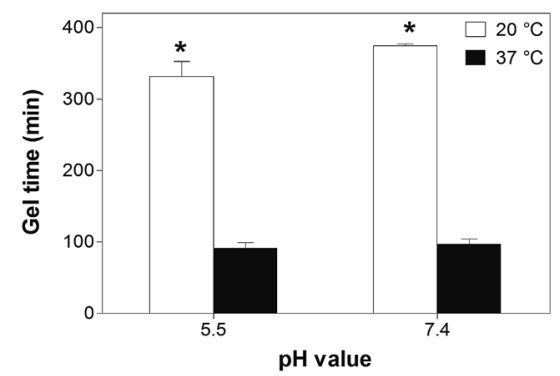

B

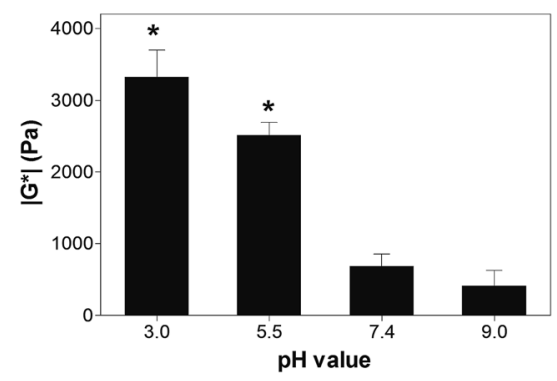

D

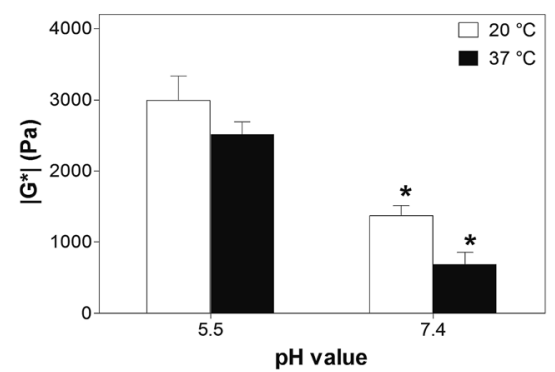

Fig. 2 Influence of the $\mathrm{pH}$ on the gel time (A) and stiffness (B) of DA hydrogels at $37^{\circ} \mathrm{C}$. Influence of the temperature on the gel time (C) and stiffness (D) of DA hydrogels at pH 5.5 and 7.4. The measurements were performed in triplicate and the results are presented as means \pm standard deviations; * indicates statistically significant differences versus all other experimental groups $(p<0.05)$.

reaction and the gel time is basically independent from the $\mathrm{pH}$. However, the cross-linking process considerably slows down after gelation and the competitive reaction becomes increasingly important. As discussed above, the rate of the ringopening reaction increases with increasing $\mathrm{pH}$; consequently, the degree of cross-linking decreases with increasing $\mathrm{pH}$. At $\mathrm{pH}$ 9.0 and $\mathrm{pH} 11.0$, the ring-opening reaction is fast compared to the DA reaction. This results in significantly prolonged gel times and low degrees of cross-linking.

Besides the $\mathrm{pH}$, the temperature is expected to influence the gelation kinetics and the degree of cross-linking of DA hydrogels. The observed gel times $(332.5 \pm 21.1 \mathrm{~min}$ at $\mathrm{pH} 5.5$ and $374.7 \pm 2.5 \mathrm{~min}$ at $\mathrm{pH} 7.4$ ) were significantly longer at $20{ }^{\circ} \mathrm{C}$ than at $37^{\circ} \mathrm{C}$ (Fig. 2C). In contrast to the gel time, the absolute value of $G^{*}$ was strongly influenced by the $\mathrm{pH}$; values between $2992 \pm 347 \mathrm{~Pa}(\mathrm{pH} 5.5)$ and $1369 \pm 148 \mathrm{~Pa}(\mathrm{pH}$ 7.4) were measured at $20{ }^{\circ} \mathrm{C}$ (Fig. 2D). Our results clearly demonstrate that increasing the temperature accelerates the DA reaction. Gelation was more than three times faster at $37^{\circ} \mathrm{C}$ than at $20^{\circ} \mathrm{C}$. Despite the lower reaction rate at $20^{\circ} \mathrm{C}$, the absolute value of $G^{*}$ was equally high or higher than at $37^{\circ} \mathrm{C}$. This can be explained by the changed hydrolytic stability of maleimides at different $\mathrm{pH}$-values and temperatures. At $\mathrm{pH}$ 5.5, the ring-opening hydrolysis of maleimides is extremely slow for both tested temperatures (Fig. 1A). Consequently, the absolute values of $G^{*}$ and hence the degrees of cross-linking were comparable at 20 ${ }^{\circ} \mathrm{C}$ and $37^{\circ} \mathrm{C}$. At $\mathrm{pH} 7.4$, however, the rate of the ring-opening reaction is strongly influenced by the temperature (Fig. 1B). The observed rate constants were approximately five times higher at $37^{\circ} \mathrm{C}$ than at $20^{\circ} \mathrm{C}\left(6.55 \times 10^{-5} \mathrm{~s}^{-1}\right.$ vs. $1.24 \times 10^{-5} \mathrm{~s}^{-1}$, Tables 1 and 2). As a result of this, the magnitude of $G^{*}$ was approximately two times higher at $20{ }^{\circ} \mathrm{C}$ than at $37^{\circ} \mathrm{C}(1369 \pm$ $148 \mathrm{~Pa} v s .685 \pm 169 \mathrm{~Pa}$ ). It can be concluded from our rheological experiments that cross-linking of DA hydrogels is best performed in slightly acidic solutions (e.g., at pH 5.5) to ensure high cross-linking degrees. Furthermore, cross-linking should be performed above room temperature $\left(e . g\right.$., at $\left.37^{\circ} \mathrm{C}\right)$ to fasten gel formation.

\section{Swelling and degradation of DA hydrogels}

DA hydrogels prepared from star-shaped PEG macromonomers degraded in phosphate buffer, $\mathrm{pH} 7.4$ at $37^{\circ} \mathrm{C}$ as reported in our previous publication. ${ }^{13}$ This was surprising since the described hydrogels, unlike other degradable DA hydrogels, ${ }^{10-12,14}$ did not contain labile ester bonds or enzymatically degradable substrates. To investigate factors influencing the stability of DA hydrogels, cross-linked gel cylinders were incubated at $37{ }^{\circ} \mathrm{C}$ and different pH-values (Fig. 3A). At pH 3.0 and pH 5.5, the mass of the incubated gel samples remained nearly constant. After approximately 10 months, the mass of hydrogels incubated at $\mathrm{pH} 5.5$ had slightly increased compared to those at $\mathrm{pH}$ 3.0. In contrast to that, hydrogels incubated at $\mathrm{pH}$ 7.4, $\mathrm{pH} 9.0$ or $\mathrm{pH} 11.0$ showed $\mathrm{pH}$-dependent swelling behavior. The mass of the samples increased exponentially until the gels dissolved after 4 days (pH 11.0), 18 days (pH 9.0) and 25 days (pH 7.4). Our experiment demonstrates that the stability of DA hydrogels strongly depends on the $\mathrm{pH}$ of the incubation medium.

The equilibrium of the DA/rDA reaction between furan and maleimide is thermally controlled (reaction I); temperatures up to $60{ }^{\circ} \mathrm{C}$ favor the forward (DA) reaction and adduct formation 
A

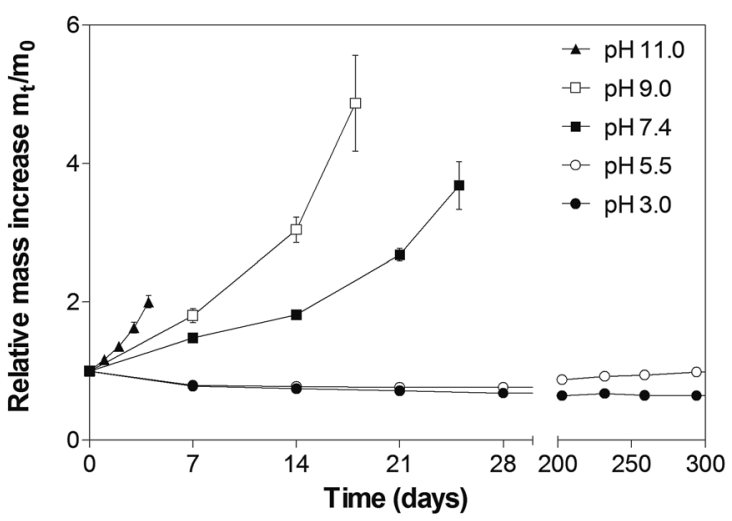

B

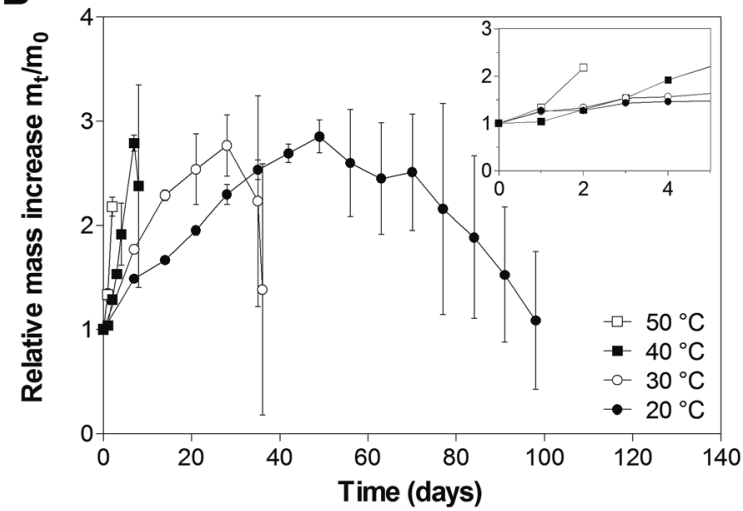

Fig. 3 Swelling and degradation of $10 \%$ (w/v) 8armPEG10k-hydrogels. Hydrogels incubated at $37{ }^{\circ} \mathrm{C}$ dissolved after 4 days ( $\left.\mathrm{pH} 11.0\right), 18$ days ( $\mathrm{pH}$ 9.0) and 25 days ( $\mathrm{pH} 7.4$ ); gels incubated at $\mathrm{pH} 5.5$ and $\mathrm{pH} 3.3$ were stable for more than 300 days (A). Hydrogels incubated at $\mathrm{pH} 7.4$ dissolved after 2 days $\left(50^{\circ} \mathrm{C}\right), 8$ days $\left(40^{\circ} \mathrm{C}\right), 36$ days $\left(30^{\circ} \mathrm{C}\right)$ and 98 days $\left(20^{\circ} \mathrm{C}\right)(\mathrm{B})$. The inset shows the relative mass increase during the first 5 days of incubation. The experiments were carried out in triplicate and the results are presented as means \pm standard deviations.

(complex 1b), whereas temperatures above $100{ }^{\circ} \mathrm{C}$ induce the reverse (rDA) reaction and the regeneration of furan and maleimide moieties (complex 1a) ${ }^{34-37}$ Therefore, hydrogel degradation at $37^{\circ} \mathrm{C}$ is most likely not solely driven by an rDA process as the reaction kinetics is too slow at body temperature. Furthermore, a DA/rDA mechanism cannot explain the observed $\mathrm{pH}$ dependence of the gel stability. The few studies investigating the $\mathrm{pH}$ dependence of the $\mathrm{DA} / \mathrm{rDA}$ reaction point towards an increased rate of the rDA reaction in the presence of Brønsted acids, ${ }^{37}$ which contradicts our observations. However, the experimental results could be explained by a $\mathrm{DA} / \mathrm{rDA}$ mechanism in combination with ring-opening hydrolysis of the generated maleimide groups (Scheme 1, degradation pathway A). Removal of maleimide groups from the $\mathrm{DA} / \mathrm{rDA}$ equilibrium, e.g., by conversion into unreactive maleamic acid derivatives (reaction IIa and IIIa), causes the DA adduct (complex 1b) to revert to the starting materials (complex 3a). In this way, the rate of the rDA reaction is increased according to Le Châtelier's principle and gel degradation is incited. ${ }^{21}$ The higher the $\mathrm{pH}$ of the incubation medium gets, the faster the maleimide groups are consumed and the faster the hydrogels dissolve. Another possible mechanism that could explain the experimental results would be the direct addition of $\mathrm{OH}^{-}$to the carbonyl moiety of the DA adduct (reaction IIb) followed by a ring-opening reaction (reaction IIIb) and rDA reaction (reaction IV, Scheme 1, degradation pathway B).

To verify our hypothesis, cross-linked hydrogels were incubated at pH 7.4 and different temperatures (Fig. 3B). Although all incubation temperatures were below the temperature usually required for the rDA reaction to proceed at a significant rate, ${ }^{34-36}$ hydrogel degradation was observed at all conditions. The gel samples dissolved after 2 days $\left(50^{\circ} \mathrm{C}\right), 8$ days $\left(40{ }^{\circ} \mathrm{C}\right), 36$ days $\left(30^{\circ} \mathrm{C}\right)$ and 98 days $\left(20^{\circ} \mathrm{C}\right)$. Assuming that hydrogel degradation follows a simple first-order process, the hydrogels should dissolve after $85 \%$ of the DA linkages have been broken, i.e., after approximately three half-lives. ${ }^{29}$ If the degradation process was actually controlled by ring-opening hydrolysis of maleimide groups, it should be possible to predict the degradation time from the observed rate constants. However, the observed values were approximately 50 times higher than the predicted values (Fig. 4). Therefore, the ring-opening reaction is most likely not the rate-determining step in the degradation process; hydrogel degradation is most likely not controlled by the ring-opening reaction. Furthermore, it should be emphasized that hydrogel degradation is most likely not adequately described by a single first-order process; additional factors, such as the cross-linking density and the branching factor of the macromonomers, must be taken into account. For example, it has been shown that the stability of hydrogels made from four-armed PEG (10 kDa molecular weight) and eight-armed PEG (20 kDa molecular weight) differs, even though the number of elastically active chains should be identical in both systems. ${ }^{13}$ In hydrogels made from four-armed PEG, the number of functional groups per branching point is lower than in eight-armed PEG gels. Consequently, the cross-linking density of four-armed PEG hydrogels decreases faster during degradation; the gel stability

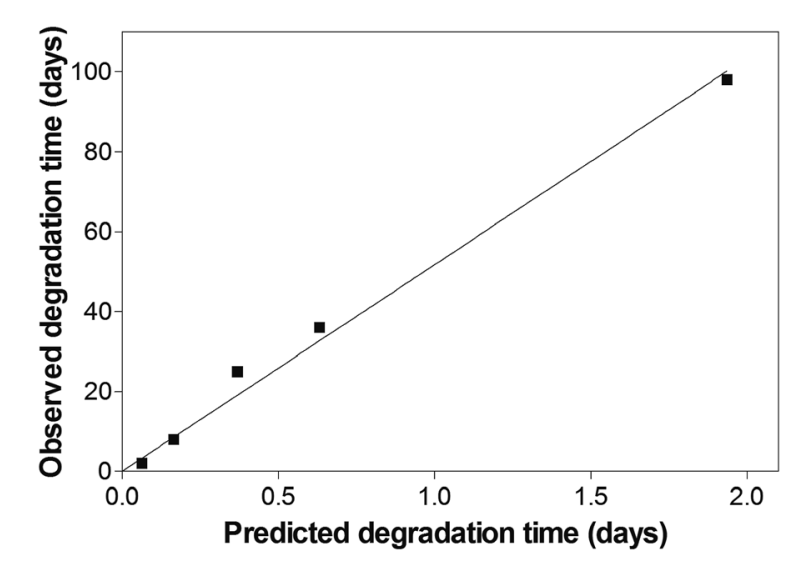

Fig. 4 Comparison of the predicted $\left(3 t_{1 / 2}\right)$ and observed degradation times at $\mathrm{pH} 7.4$ and different temperatures. The solid line represents a least-squares fit of a linear equation to the data points. The observed values were approximately 50 times higher than the predicted values. 
is greatly reduced. The experimental findings would fully support the proposed degradation pathway A. The degradation of DA hydrogels is based on the DA/rDA equilibrium, with the rDA reaction most likely being the rate-determining step. Increasing the temperature catalyzes the ring-opening hydrolysis of maleimide groups; consequently, the rate of the rDA reaction is increased and gel degradation is incited without requiring elevated temperatures.

\section{Molecular modeling studies}

Modeling the actual degradation process of hydrogels is a great challenge because of the extremely large box size and, consequently, large number of sites that are required to describe the system. Even qualitative results can hardly be achieved, especially if formation and breaking of bonds should be taken into account. Therefore, only the reactive moieties were considered in the SEMD simulations. Further extending the system, e.g., by adding ethylene glycol units, may produce artificial results. In SEMD simulations, side chains next to the reactive center are flexible; oxygen atoms may form hydrogen bonds with water to direct the addition of $\mathrm{OH}^{-}$to the maleimide portion of the DA adduct. In highly swollen gel networks, however, the polymer chains are stretched and restricted in their movement. Therefore, it is acceptable to reduce the polymer structures of 8armPEG10k-furan and 8armPEG10k-maleimide to 2-methylfuran and $\mathrm{N}$-methylmaleimide, respectively, without compromising the validity of the model. Fig. 5 shows possible reaction

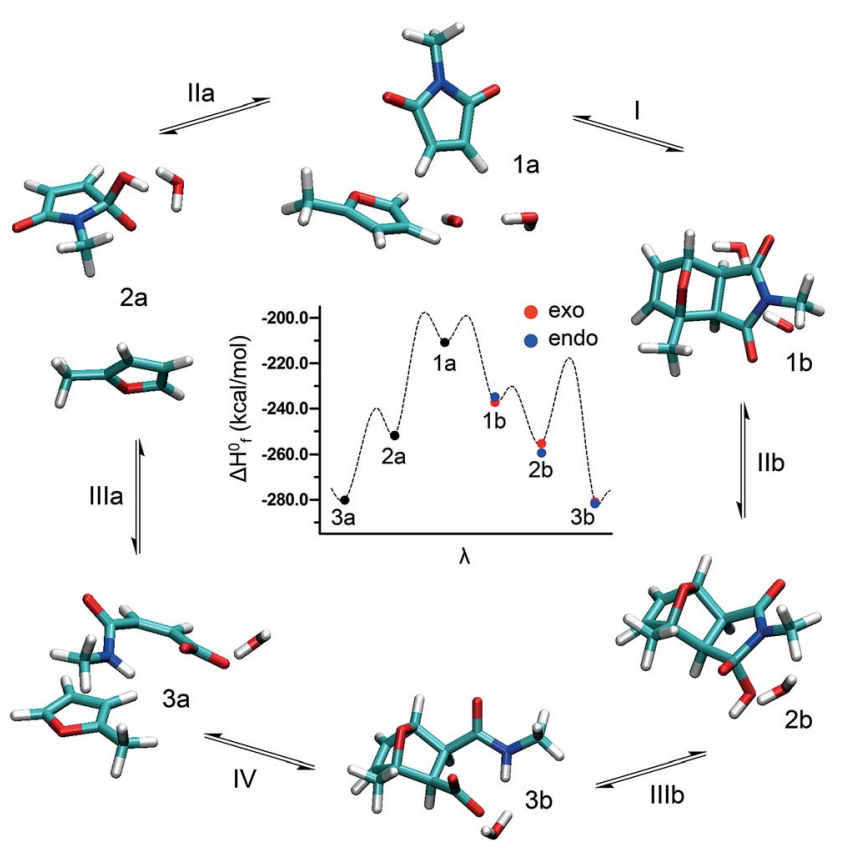

Fig. 5 Possible reaction pathways connecting different maleimide/ furan-complexes in the presence of a water molecule and an $\mathrm{OH}^{-}$ion. The schematic energy diagram in the center is based on the semiempirical calculation of the enthalpy of formation. The exo isomer is marked by red dots and the endo isomer is marked by blue dots; no significant energetic differences were observed between the two isomers. For reasons of clarity, only the chemical structures of the exo isomers are shown. pathways connecting different maleimide/furan-complexes in the presence of a water molecule and an $\mathrm{OH}^{-}$ion. Furthermore, a corresponding schematic energy diagram based on the semi-empirical calculation of the enthalpy of formation is depicted in the center of Fig. 5. The calculations predict that the DA adduct $\mathbf{1 b}$ is enthalpically favored compared to complex $\mathbf{1 a}$. This is in agreement with the experimental results showing the formation of the DA adduct from maleimide and furan. Addition of $\mathrm{OH}^{-}$to the carbonyl moiety of the DA adduct would lead to a further enthalpic stabilization (complex 2b), as indicated by semi-empirical calculations. The calculations further indicate that the ring-open complex $\mathbf{3 b}$ would be enthalpically favored compared to complex $2 \mathbf{b}$. In addition to the exo adduct, the formation of the endo isomer also has to be considered. However, semi-empirical calculations predicted no significant differences in the standard enthalpy of formation between the corresponding endo and exo isomers. Because of the DA/rDA equilibrium, a second pathway must be considered. Addition of the $\mathrm{OH}^{-}$to the carbonyl moiety of the maleimide (complex 2a) and the subsequent ring opening would lead to a strong enthalpic stabilization (complex 3a). Since no hydrogel formation was observed between 8armPEG10k-furan and the ring-open form of 8armPEG10kmaleimide (results of the rheological experiments not shown), the formation of complex $\mathbf{3} \mathbf{b}$ from complex $\mathbf{3 a}$ cannot be suggested.

To investigate which pathway hydrogel degradation most likely follows, the $\mathrm{OH}^{-}$-catalyzed ring-opening hydrolysis of maleimide was simulated (reaction IIIa). Fig. 6A shows the progress in the ring-opening reaction, based upon the distances of relevant atoms marked by $\mathrm{C}, \mathrm{H}, \mathrm{O}$ and $\mathrm{N}$, as a function of time for the model system $N$-methylmaleimide. At an early state of the reaction, the length of the $\mathrm{C}-\mathrm{O}$ bond decreases, whereas the distance between the carbon and the nitrogen atom increases, indicating the cleavage of the $\mathrm{C}-\mathrm{N}$ bond. After a period of about $1750 \mathrm{fs}$, the hydrogen atom of the $\mathrm{OH}^{-}$-group approaches the nitrogen atom, resulting in a significant step of the $\mathrm{H}-\mathrm{N}$-distance function. Afterwards, the proton transfer from the oxygen atom to the nitrogen atom takes place, yielding the product $N$-methylmaleamic acid anion. In contrast to the semi-empirical MD simulation of $N$-methylmaleimide, ring opening of complex $2 \mathbf{b}$ was not observed (Fig. 6B), although the ring-open complex $3 \mathbf{b}$ would be enthalpically favored compared to complex $\mathbf{2 b}$. Thus, it can be concluded that the formation of the DA adduct $\mathbf{1 b}$ from complex 1a may be kinetically controlled. A reason for the resistance of complex $\mathbf{2} \mathbf{b}$ towards ring opening may be a large change in the dihedral angle $\delta$. As observed for $N$-methylmaleimide, the dihedral angle $\delta$ undergoes a strong change from $\sim 1^{\circ}$ to $\sim 56^{\circ}$ (Fig. $6 \mathrm{~A}$ ). In contrast to that, such a large change in the dihedral angle is not possible for complex 2b because of the rigid ring system. Based on SEMD simulations it can be concluded that hydrogel degradation most likely follows pathway A (Scheme 1). Addition of $\mathrm{OH}^{-}$to the carbonyl moiety of the DA adduct followed by a ring-opening reaction and $\mathrm{rDA}$ reaction (Scheme 1 , degradation pathway $\mathrm{B}$ ) cannot be suggested. 


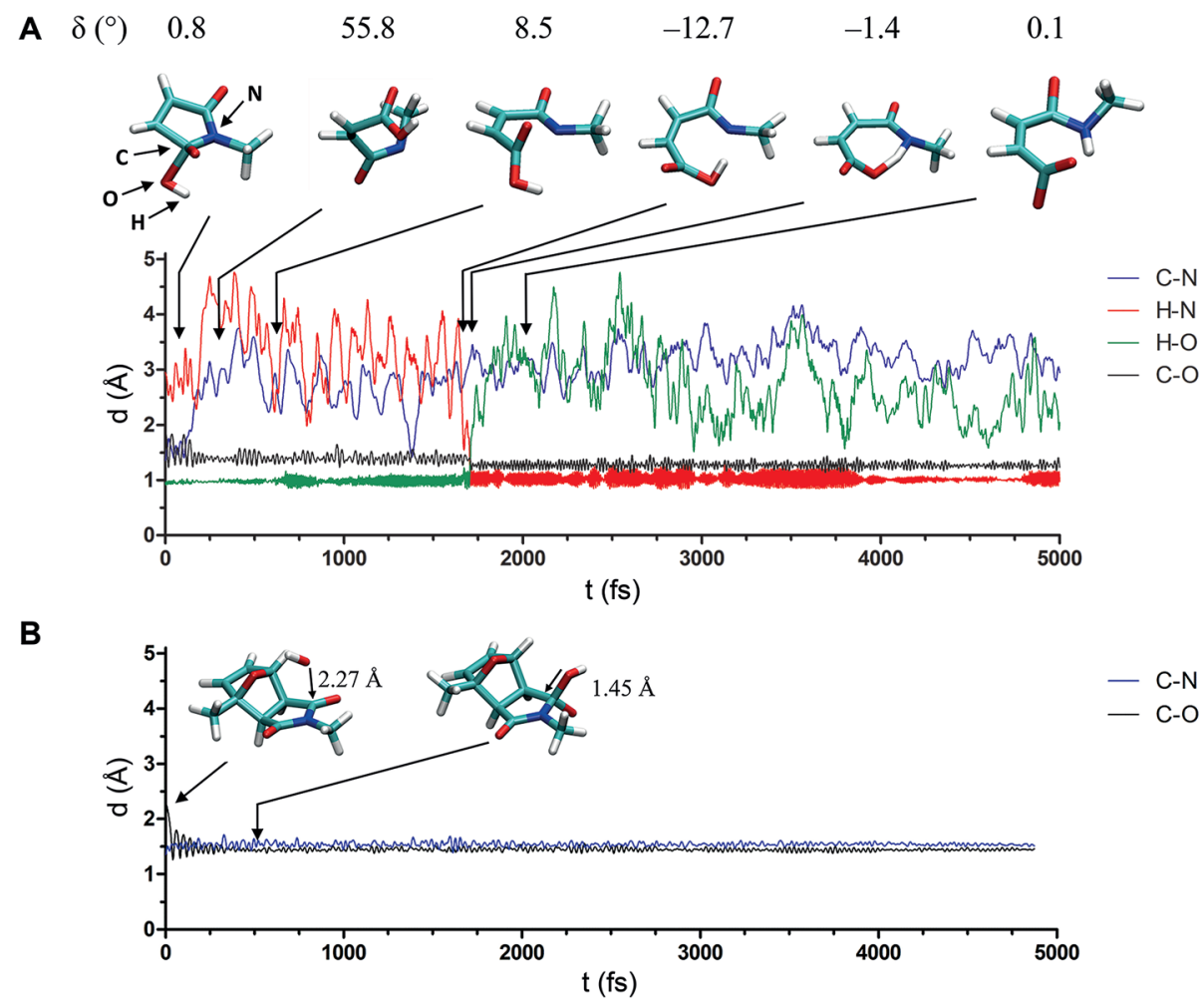

Fig. 6 Semi-empirical MD simulations of the ring-opening reaction. The distances of relevant atoms marked by $\mathrm{C}, \mathrm{H}, \mathrm{O}$ and $\mathrm{N}$ are shown as a function of time for the model systems $N$-methylmaleimide (A) and complex $2 \mathrm{~b}$ (B).

\section{Conclusion}

In this study we investigated the influence of $\mathrm{pH}$ and temperature on the cross-linking and degradation behavior of DA hydrogels. Rheological experiments and swelling studies were supplemented with SEMD simulations. Taken together, the results of our studies show that degradation of DA hydrogels occurs by rDA reaction and subsequent $\mathrm{OH}^{-}$-catalyzed ringopening hydrolysis of the formed maleimides to unreactive maleamic acid derivatives (Scheme 1, degradation pathway A). The instability of the involved maleimides directly affects the cross-linking and degradation behavior of DA hydrogels, with $\mathrm{pH}$ and temperature being the main influencing factors. These findings have implications for other biomaterials that are crosslinked by DA reactions, especially hydrogels. Cross-linking is best performed in slightly acidic solutions (e.g., at pH 5.5) to ensure high degrees of conversion. Furthermore, cross-linking should be performed above room temperature $\left(\right.$ e.g. , at $\left.37^{\circ} \mathrm{C}\right)$ to fasten the gelation process. When placed into a physiological environment (e.g., in aqueous solution at $\mathrm{pH} 7.4$ and $37^{\circ} \mathrm{C}$ ), degradability of the cross-linked hydrogels must be considered. Removal of maleimide groups from the DA/rDA equilibrium by ring-opening hydrolysis increases the rate of the rDA reaction according to Le Châtelier's principle. This evades the need for high temperatures to incite the rDA reaction, allowing the synthesis of biomaterials that readily degrade at physiological conditions. We are fully aware that in vitro experiments cannot exactly predict the degradation behavior of DA hydrogels in potential applications, e.g. when applied as a biomaterial in vivo. Nevertheless, we expect that DA hydrogels will be degraded in vivo, with the $\mathrm{pH}$ of the tissue having a major influence on the degradation time. Further experiments to investigate the in vivo compatibility and degradability of PEG-based DA hydrogels will be run in the near future and presented in an upcoming publication.

\section{Acknowledgements}

The financial support from the German Research Foundation (DFG), grant number GO 565/16-1 is gratefully acknowledged.

\section{References}

1 B. S. Sumerlin and A. P. Vogt, Macromolecules, 2010, 43, 1-13. 2 P. L. Golas and K. Matyjaszewski, Chem. Soc. Rev., 2010, 39, 1338-1354.

3 C. M. Nimmo and M. S. Shoichet, Bioconjugate Chem., 2011, 22, 2199-2209.

4 W. Xi, T. F. Scott, C. J. Kloxin and C. N. Bowman, Adv. Funct. Mater., 2014, 24, 2572-2590.

5 M. A. Tasdelen, Polym. Chem., 2011, 2, 2133-2145.

6 A. Gandini, Prog. Polym. Sci., 2013, 38, 1-29.

7 M. Shi, J. H. Wosnick, K. Ho, A. Keating and M. S. Shoichet, Angew. Chem., 2007, 119, 6238-6243.

8 M. Shi and M. S. Shoichet, J. Biomater. Sci., Polym. Ed., 2008, 19, 1143-1157. 
9 M. Shi, K. Ho, A. Keating and M. S. Shoichet, Adv. Funct. Mater., 2009, 19, 1689-1696.

10 H.-L. Wei, K. Yao, H.-J. Chu, Z.-C. Li, J. Zhu, Y.-M. Shen, Z.-X. Zhao and Y.-L. Feng, J. Mater. Sci., 2012, 47, 332-340.

11 C. M. Nimmo, S. C. Owen and M. S. Shoichet, Biomacromolecules, 2011, 12, 824-830.

12 H. Tan, J. P. Rubin and K. G. Marra, Macromol. Rapid Commun., 2011, 32, 905-911.

13 S. Kirchhof, F. P. Brandl, N. Hammer and A. M. Goepferich, J. Mater. Chem. B, 2013, 1, 4855-4864.

14 F. Yu, X. Cao, L. Zeng, Q. Zhang and X. Chen, Carbohydr. Polym., 2013, 97, 188-195.

15 S. D. Bergman and F. Wudl, J. Mater. Chem., 2007, 18, 41-62.

16 S. Burattini, B. W. Greenland, D. Chappell, H. M. Colquhoun and W. Hayes, Chem. Soc. Rev., 2010, 39, 1973-1985.

17 Y.-L. Liu and T.-W. Chuo, Polym. Chem., 2013, 4, 2194-2205.

18 G. Mantovani, F. Lecolley, L. Tao, D. M. Haddleton, J. Clerx, J. J. L. M. Cornelissen and K. Velonia, J. Am. Chem. Soc., 2005, 127, 2966-2973.

19 T. Dispinar, R. Sanyal and A. Sanyal, J. Polym. Sci., Part A: Polym. Chem., 2007, 45, 4545-4551.

20 I. Kosif, E.-J. Park, R. Sanyal and A. Sanyal, Macromolecules, 2010, 43, 4140-4148.

21 A. A. Kislukhin, C. J. Higginson, V. P. Hong and M. G. Finn, J. Am. Chem. Soc., 2012, 134, 6491-6497.

22 K. C. Koehler, K. S. Anseth and C. N. Bowman, Biomacromolecules, 2013, 14, 538-547.
23 K. C. Koehler, D. L. Alge, K. S. Anseth and C. N. Bowman, Biomaterials, 2013, 34, 4150-4158.

24 F. Yu, X. Cao, Y. Li, L. Zeng, B. Yuan and X. Chen, Polym. Chem., 2014, 5, 1082-1090.

25 S.-Y. Tang, J. Shi and Q.-X. Guo, Org. Biomol. Chem., 2012, 10, 2673-2682.

26 R. G. Barradas, S. Fletcher and J. D. Porter, Can. J. Chem., 1976, 54, 1400-1404.

27 S. Matsui and H. Aida, J. Chem. Soc., Perkin Trans. 2, 1978, 1277-1280.

28 M. N. Khan, J. Pharm. Sci., 1984, 73, 1767-1771.

29 G. M. Kavanagh and S. B. Ross-Murphy, Prog. Polym. Sci., 1998, 23, 533-562.

30 A. Wassermann, J. Chem. Soc., 1942, 623.

31 A. Wassermann, J. Chem. Soc., 1946, 1089-1090.

32 W. Rubin, H. Steiner and A. Wassermann, J. Chem. Soc., 1949, 3046-3057.

33 E. B. Mubofu and J. B. F. N. Engberts, J. Phys. Org. Chem., 2004, 17, 180-186.

34 J. R. McElhanon and D. R. Wheeler, Org. Lett., 2001, 3, 26812683.

35 A. Gandini, D. Coelho and A. J. Silvestre, Eur. Polym. J., 2008, 44, 4029-4036.

36 X. Liu, P. Du, L. Liu, Z. Zheng, X. Wang, T. Joncheray and Y. Zhang, Polym. Bull., 2013, 70, 2319-2335.

37 A. Maggiani, A. Tubul and P. Brun, Chem. Commun., 1999, 2495-2496. 